\title{
Contribuições para a gestão do patrimônio cultural a partir do estudo das representações sociais
}

\author{
Cibele Piva Ferrari \\ André de Souza de Lima \\ Sandra Paschoal Leite de Camargo Guedes
}

Resumo: O presente artigo apresenta os resultados da pesquisa que buscou, através de um estudo interdisciplinar, envolvendo geografia, história e psicologia social, identificar o patrimônio cultural do Distrito do Saí, em São Francisco do Sul, Santa Catarina. Através da identificação espacial desse patrimônio pode-se contribuir para a elaboração de políticas públicas direcionadas às potencialidades destacadas para a preservação do mesmo, bem como a integração de todo o patrimônio cultural do município. Além de mapas temáticos do Distrito do Saí, uma proposta de setorização por localidade foi criada, permitindo conhecer onde se concentra o patrimônio cultural no Distrito, que é diverso e representante de diferentes períodos, tais como os Sambaquis, ruínas relativas à ocupação nos séculos XVII e XVIII, bem como engenhos e igrejas, além dos saberes locais. A identificação desse patrimônio permitirá que ele seja incluído nas atividades da gestão municipal.

Palavras-chave: Patrimônio Cultural. Geoprocessamento. Representações Sociais. São Francisco do Sul; Distrito do Saí.

\section{Contributions to the management of cultural heritage from the study of social representations}

Abstract: This article presents the outcome of the research that has searched, through of an interdisciplinary study, involving geography, history and social psychology, identify the cultural heritage of Distrito do Saí [Saí's district], in São Francisco do Sul, Santa Catarina. The spatial identification of this heritage can contribute to the development of public policies directed highlighted the potential for the preservation of the same, well as the integration of the entire cultural heritage of the city. Well as thematic maps of the Distrito do Saí [Saí's district], a proposed sectorization by locality was created, allowing to know where concentrates the cultural heritage in the District, that is diverse and representative of different periods, such as Sambaquis, ruins regarding the occupation in the seventeenth and eighteenth centuries, as well as mills and churches, as well as local knowledge. Identifying of this heritage will allow it to be included in the activities of municipal management.

Keywords: Cultural Heritage. Geoprocessing. Social Representations. São Francisco do Sul. Distrito do Saí [Saí's district].

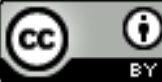

Esta obra foi licenciada sob uma Licença Creative Commons - Atribuição 3.0 Não Adaptada. 


\section{O estudo interdisciplinar do patrimônio cultural - representações sociais e geoprocessamento}

O presente artigo visa apresentar os resultados da pesquisa que buscou, através de um estudo interdisciplinar, envolvendo geografia, história e psicologia social, identificar o patrimônio cultural do Distrito do Saí, em São Francisco do Sul, Santa Catarina. O patrimônio cultural está inserido em um debate sobre valores, sentidos, usos e significados. Entendendo que são os indivíduos que lhe atribuem estes valores dentro de um campo de disputas, afirmação e legitimação de memórias e identidades. Segundo Sandra Pellegrini (2009) são as memórias do passado que fundamentam a coesão entre os indivíduos e também são elas que evidenciam as diferenças culturais. $\mathrm{O}$ direito à memória, refletida no patrimônio cultural de diversos grupos, está diretamente ligado à formação do indivíduo enquanto cidadão, pois pressupõe o reconhecimento da diversidade e necessidade de convivência entre grupos com características culturais distintas. Maria Ângela Salvadori (2008) descreve o patrimônio cultural como uma construção derivada da memória social, que colabora na formação de identidades que influenciam no modo como os indivíduos se apropriam da realidade.

A identificação do patrimônio cultural apresenta-se como uma importante forma de atuar sobre a gestão da memória e da identidade de um lugar. O que pode ser considerado patrimônio cultural de um município, estado ou país? Quais os critérios para defini-los? Certamente não basta o registro, é necessário saber o que deve ser registrado, quais os bens que a sociedade identifica como representantes de suas memórias e identidades. Os estudos relacionados ao Patrimônio Cultural devem levar em conta a multiplicidade de aspectos que existem nas relações estabelecidas entre o local, a população e os usos deste patrimônio, bem como as referências materiais e imateriais advindas disto. Desta forma, considera-se que o estudo do patrimônio cultural é interdisciplinar por essência. Acredita-se que a partir da análise das representações sociais seja possível identificar o que a sociedade considera como seu patrimônio cultural.

A Teoria das Representações Sociais, desenvolvida por Serge Moscovici dentro da Psicologia Social na década de 1960, possibilita que seja compreendido como a sociedade se apropria do seu patrimônio cultural, contribuindo para seu estudo e orientando decisões a respeito de sua gestão. As representações sociais refletem a maneira como os indivíduos pensam, agem e procuram compreender o sentido de suas ações e pensamentos, e "todas as interações humanas, surjam elas entre duas pessoas ou entre dois grupos, pressupõem representações. Na realidade, é isso que as caracteriza" (MOSCOVICI, 2009, p. 40). As representações sociais têm como funções, segundo o autor, convencionalizar os objetos, descrever, classificar e explicar a realidade. E dessas funções se desdobram outras: comunicação, orientação e justificação de comportamentos, identificação e integração do novo, equilíbrio cognitivo e social, bem como de normativa das relações intergrupais (RODRÍGUEZ, 2004).

Essa teoria propõe uma visão global das relações e do comportamento dos indivíduos, o que contribui para uma maior compreensão da realidade e ação sobre a mesma. Explica os processos relacionados à criação de conceitos básicos como sentido comum, vida cotidiana e linguagens, mostrando como se organiza o pensamento que culmina em uma determinada representação que é compartilhada por um determinado grupo social. 
O conhecimento da região através de dados históricos, das representações sociais e do geoprocessamento dessas informações, constitui importante ferramenta para a gestão do seu patrimônio cultural. A identificação do patrimônio cultural reconhecido pela população possibilita que a gestão municipal amplie a sua área de atuação, revendo as prioridades de investimento e fomento cultural.

O geoprocessamento é utilizado em diversas áreas do conhecimento, pelos mais distintos profissionais, através de análises espaciais e confecção de mapas que possibilitem identificar as demandas e as potencialidades específicas a cada localidade. Essa ferramenta caracteriza e qualifica o território, auxiliando nos processos de gestão do espaço. As técnicas utilizadas são descritas por Ferreira et al (2011) como ferramentas de integração de tecnologias, onde a aquisição de informações e o seu tratamento posterior a transformam. Desta maneira, os dados cartográficos utilizados na elaboração de mapas, juntamente com os dados alfanuméricos, se tornam informações geográficas.

Dentre as diversas aplicações para o uso do geoprocessamento, destaca-se o planejamento e gestão do espaço urbano. A utilização de mapas para conhecer a infraestrutura disponível para a população e assim identificar áreas carentes da atenção pública é cada vez mais comum. Essa atenção voltada para a área urbana é regida por leis que regulamentam e estabelecem as diretrizes gerais presentes na Constituição Federal, como por exemplo, a Lei $\mathrm{n}^{\mathrm{o}} 10.257$ de 10 de Julho de 2001, conhecida por criar uma ferramenta básica que norteia e estabelece objetivos para desenvolver o espaço urbano, ou seja, o Plano Diretor. Dentre todos os itens dessa Lei, nas mais variadas segmentações do que compete à gestão pública, destaca-se:

Art. $2^{\circ}$ A política urbana tem por objetivo ordenar o pleno desenvolvimento das funções sociais da cidade e da propriedade urbana, mediante as seguintes diretrizes gerais:

$[\ldots]$

XII - proteção, preservação e recuperação do meio ambiente natural e construído, do patrimônio cultural, histórico, artístico, paisagístico e arqueológico.

O Instituto do Patrimônio Histórico e Artístico Nacional (IPHAN) também estabelece normas para a gestão e o planejamento do espaço urbano, dentre elas pode-se destacar a Lei no 6.766 de 19 de dezembro de 1979, que dispõe sobre o parcelamento do solo urbano:

Art. $13^{\circ}$ Caberão aos Estados o exame e a anuência prévia para aprovação, pelos Municípios, de loteamento e desmembramento nas seguintes condições:

I - Quando localizados em áreas de interesse especial, tais como as de proteção aos mananciais ou patrimônio cultural, histórico, paisagístico e arqueológico, assim definidas por legislação estadual ou federal.

Desta forma, é possível apontar que a proteção do patrimônio cultural nos municípios está prevista em lei, mas, na maioria das vezes, o desconhecimento do que seja patrimônio cultural e/ou onde ele se localiza, são empecilhos à sua proteção. Cabe ao poder executivo municipal conhecer onde está localizado o seu patrimônio cultural, tarefa bastante árdua e que requer metodologia adequada. 
Segundo Moura (2003), a utilização do geoprocessamento na gestão do patrimônio cultural permite à gestão pública ter uma visão holística da realidade de maneira didática e muito ágil. A autora afirma que a partir do momento que se tem as informações espacializadas é possível gerir e monitorar, com rigidez, intervenções no patrimônio. Além disso, é possível identificar as potencialidades da estrutura desse patrimônio a fim de explorá-lo turisticamente, incrementando, assim, a receita do município e da população local.

\section{O patrimônio cultural do Distrito do Saí}

O município de São Francisco do Sul está situado no litoral norte do estado de Santa Catarina e é um dos seis municípios banhados pelas águas do sistema estuarino baía Babitonga. O território do município possui 498,6 $\mathrm{km}^{2}$ e é constituído pela península de São Francisco do Sul, sede do município e pelo Distrito do Saí, localizado na porção continental (Figura 1).

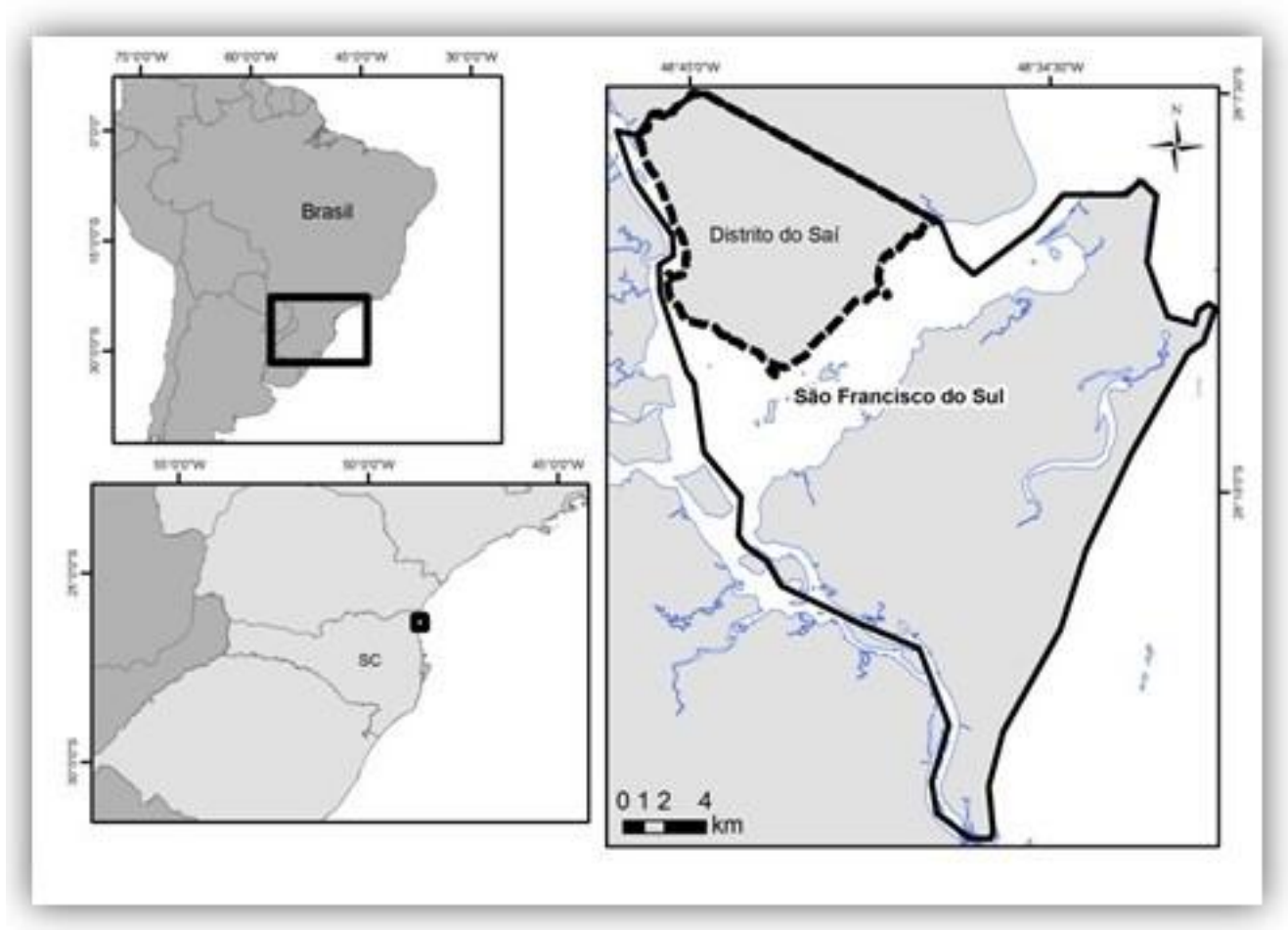

Figura 1: Localização de São Francisco do Sul, com destaque para o Distrito do Saí. Fonte: André Lima, Grupo de Estudos Interdisciplinares de Patrimônio Cultural, 2013.

O Distrito do Saí, localizado entre as coordenadas $26^{\circ} 12^{\prime}$ de latitude sul e $48^{\circ} 42^{\prime}$ de longitude oeste, é responsável por toda a água potável distribuída para o município através de canos submersos. O Distrito é composto pelas localidades de Vila da Glória, Ilha Alvarenga, Praia Bonita, Estaleiro, Frias, Ramos, Torno dos Pintos, Caeté, Lamin, Ilha da Rita e Saí Mirim e por duas ilhas: a Ilha da Rita e a Ilha Alvarenga, conforme pode ser visto na Figura 2. Entre o Distrito do Saí e a sede do município o acesso é feito através de balsa e barcos, ou por rodovias e vias urbanas que passam por outros municípios. Apesar da existência de um corpo hídrico que distancia em, 
aproximadamente, quatro quilômetros da área continental, a integração da população, segundo os próprios moradores, não é dificultada por problemas de acesso. Este fato se justifica já que a população, em sua maioria, tem relação estreita com o mar, devido as várias atividades econômicas da região estarem envolvidas com a pesca e com a malacocultura ${ }^{1}$. Dessa maneira, a distância é facilmente superada pela população do município de São Francisco do Sul por via marítima.

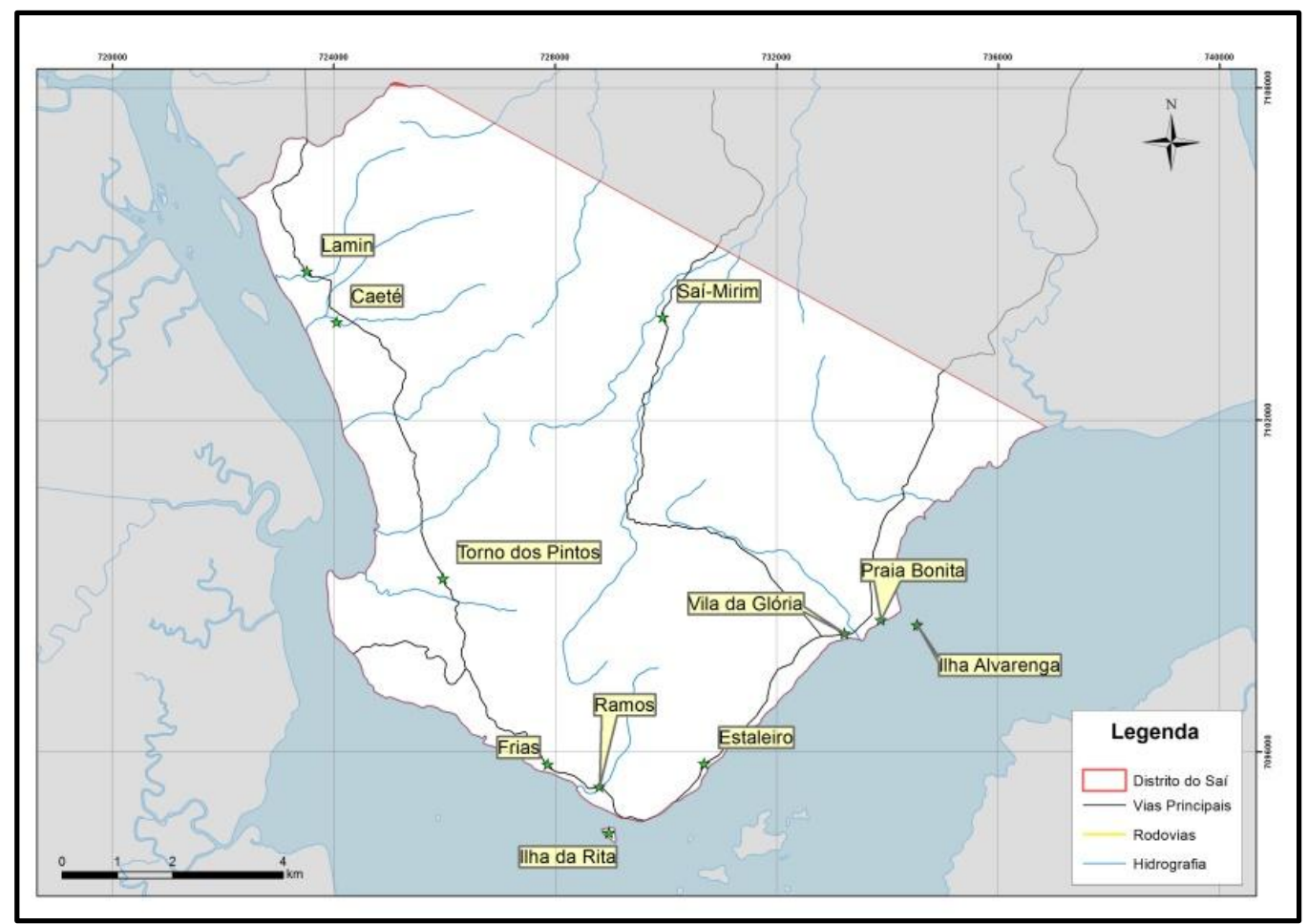

Figura 2: Localidades do Distrito do Saí.

Fonte: André Lima, Grupo de Estudos Interdisciplinares de Patrimônio Cultural, 2013.

Para viabilizar o trabalho de mapeamento e catalogação do patrimônio cultural do Distrito do Saí, foi necessário um reconhecimento da região, com base em registros oriundos de pesquisas pretéritas e de informações públicas do município de São Francisco do Sul. Além disto, foi utilizado o diagnóstico arqueológico da região realizado pelas arqueólogas Maria Cristina Alves e Francine Cristina Martins (2006) que identifica todos os sambaquis da região, entre outras unidades patrimoniais, bem como a pesquisa acadêmica realizada por Fernanda Mara Borba (2014) que identificou e analisou sítios históricos na região.

A pesquisa de campo foi iniciada com a aplicação de 300 formulários e a realização de 18 entrevistas gravadas a partir da metodologia da história oral. Os dados foram tabulados permitindo assim o cruzamento e interpretação dos dados obtidos. Com isso, objetivou-se identificar e analisar as representações sociais da população de São Francisco do Sul sobre o patrimônio cultural do Distrito do Saí. A partir desses resultados foi possível identificar junto à população os espaços patrimoniais

${ }^{1}$ A malacocultura é entendida como a criação ou cultivo de moluscos. 
reconhecidos por ela, bem como investigar suas memórias e representações. Foram relacionados 36 pontos de interesse para o registro nesta pesquisa e registrados com a utilização de um receptor GNSS $^{2}$. Todas as principais vias foram visitadas, bem como grande parte das vias secundárias.

Dessa forma pôde-se perceber a rede de relações que a população local estabelece com o patrimônio cultural, e os resultados da pesquisa mostraram que o patrimônio cultural do Distrito do Saí é diverso, sendo constituído por um rico patrimônio natural, além de sambaquis, ruínas relativas à ocupação nos séculos XVII e XVIII, bem como engenhos e igrejas. O patrimônio imaterial está relacionado às práticas e conhecimentos locais, tais como o modo de fazer a farinha de mandioca, a construção de canoas, a pesca artesanal, entre outros.

Este patrimônio é disperso e pouco conhecido, até mesmo pela gestão municipal, ao contrário do que ocorre na Ilha de São Francisco do Sul onde há um vasto patrimônio cultural reconhecido, composto pelo Centro Histórico que é tombado pelo Instituto do Patrimônio Histórico e Artístico Nacional desde 1987. O Centro Histórico de São Francisco do Sul é um patrimônio reconhecido pela população da cidade, que potencializa a identidade coletiva, e que teve forte apoio do governo federal por meio do IPHAN e do Programa Monumenta ${ }^{3}$ para sua preservação (SILVA, 2010). Para além desse patrimônio que é composto por casarios remanescentes da ocupação luso brasileira dos séculos XVIII e XIX, existe, ainda, muito a ser conhecido e identificado, principalmente na porção continental do município. A identificação do patrimônio cultural do Distrito do Saí aqui apresentada, poderá auxiliar nas atividades da gestão municipal, tanto relacionadas ao fomento das manifestações culturais do município quanto na sua inclusão na agenda turística.

O resultado do trabalho de campo possibilitou a espacialização de todos os pontos de interesse e a elaboração de mapas temáticos, a fim de conhecer a localidade onde se encontram cada um dos pontos. Toda a produção cartográfica foi realizada com a utilização do software ArcGIS 10 .Após o mapeamento de todas as localidades do Distrito do Saí foi elaborada uma proposta de setorização que pode ser visualizada na Figura 3. Esta setorização foi proposta com base nas distâncias entre as localidades utilizando a ferramenta polígonos de Thíessem, onde qualquer lugar dentro de um dos setores está mais perto do ponto associado à localidade do que a qualquer outra (ESRI, 2010).

${ }^{2}$ GNSS - Global Navigation Satellite Systems termo genérico utilizado para os sistemas de localização geoespacial.

${ }^{3}$ Ação de recuperação sustentável do patrimônio histórico urbano brasileiro sob tutela federal na qual os recursos para que os proprietários restaurassem seus imóveis são originários de um contrato de empréstimo com o Banco Interamericano de Desenvolvimento e o Governo Federal (PAULI, 2010). 


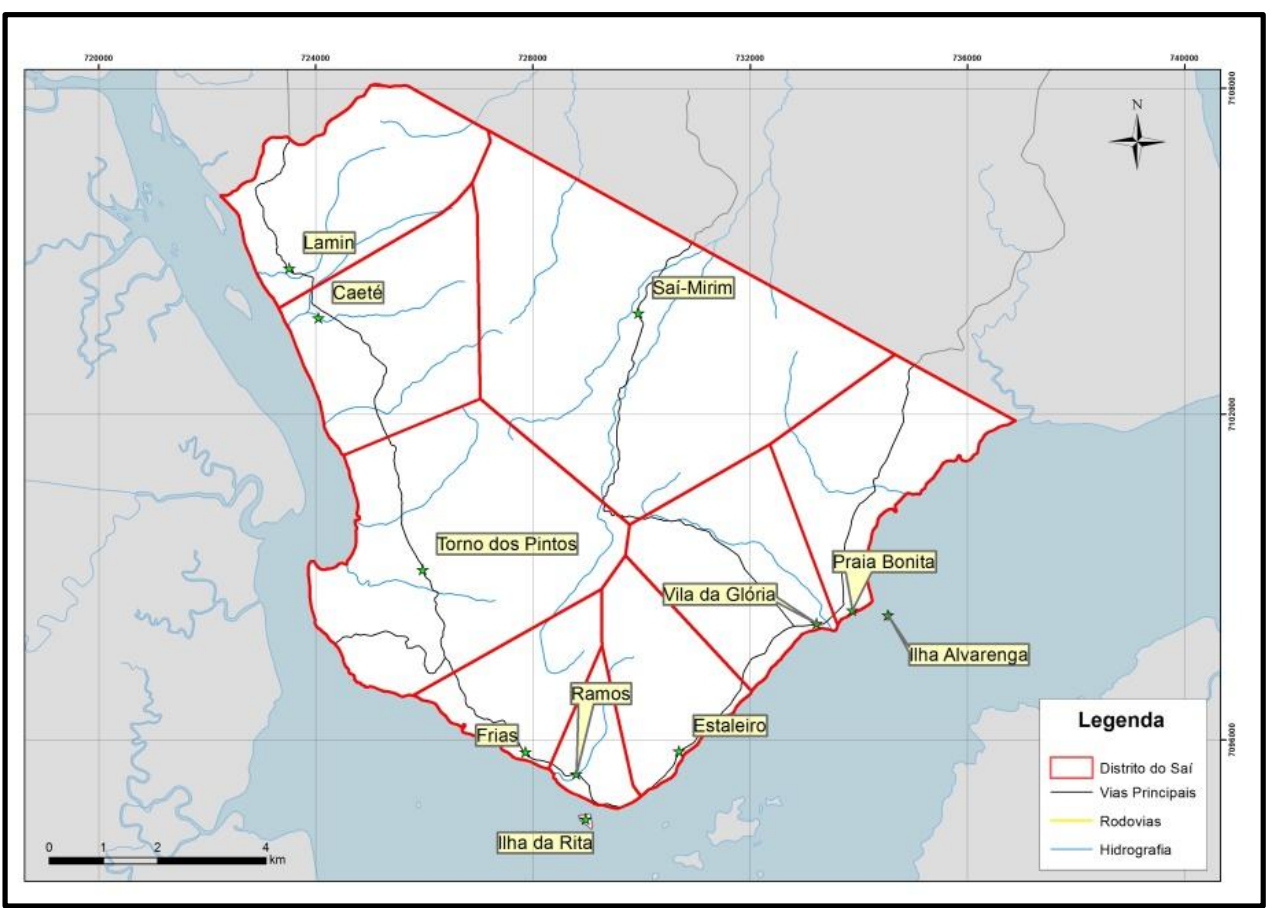

Figura 3: Setorização do Distrito do Saí.

Fonte: André Lima, Grupo de Estudos Interdisciplinares de Patrimônio Cultural, 2013.

Com a localização dos 36 pontos, foi possível observar que as localidades de Vila da Glória e Estaleiro possuem um maior número de unidades de patrimônio cultural reconhecidos pela população, bem como a região da Praia Bonita, concentra um maior número de ocorrências de sambaquis, conforme pode ser visto na Figura 4.

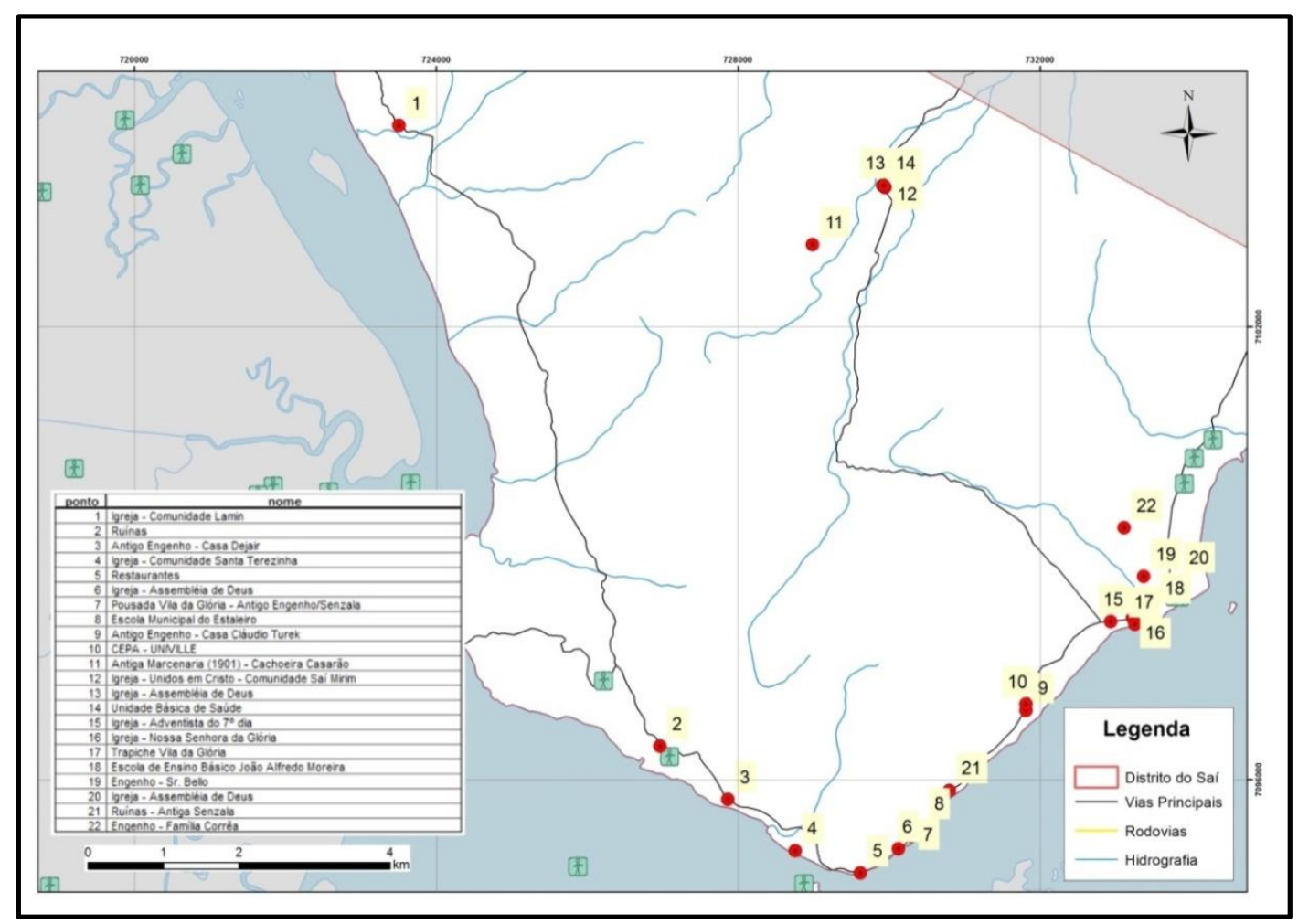

Figura 4: Localização do Patrimônio cultural no Distrito do Saí

Fonte: André Lima, Grupo de Estudos Interdisciplinares de Patrimônio Cultural, 2013. 
Um dos bens identificados pela pesquisa e um patrimônio cultural com forte apelo que insere a região no contexto da $2^{\text {a }}$ Guerra Mundial está localizado a 200 metros do Distrito do Saí, que é a Ilha da Rita (Figura 5). Durante o conflito mundial a Ilha da Rita foi utilizada como base naval, servindo de ponto de abastecimento de água potável, carvão e óleo aos navios. Conforme destacado por Roberta Nabuco de Oliveira (2013), a construção da base naval no local também ia ao encontro das preocupações do Exército Brasileiro com a região que contava com uma grande população de imigrantes alemães, causando grande apreensão ao governo de Vargas (OLIVEIRA, 2013).

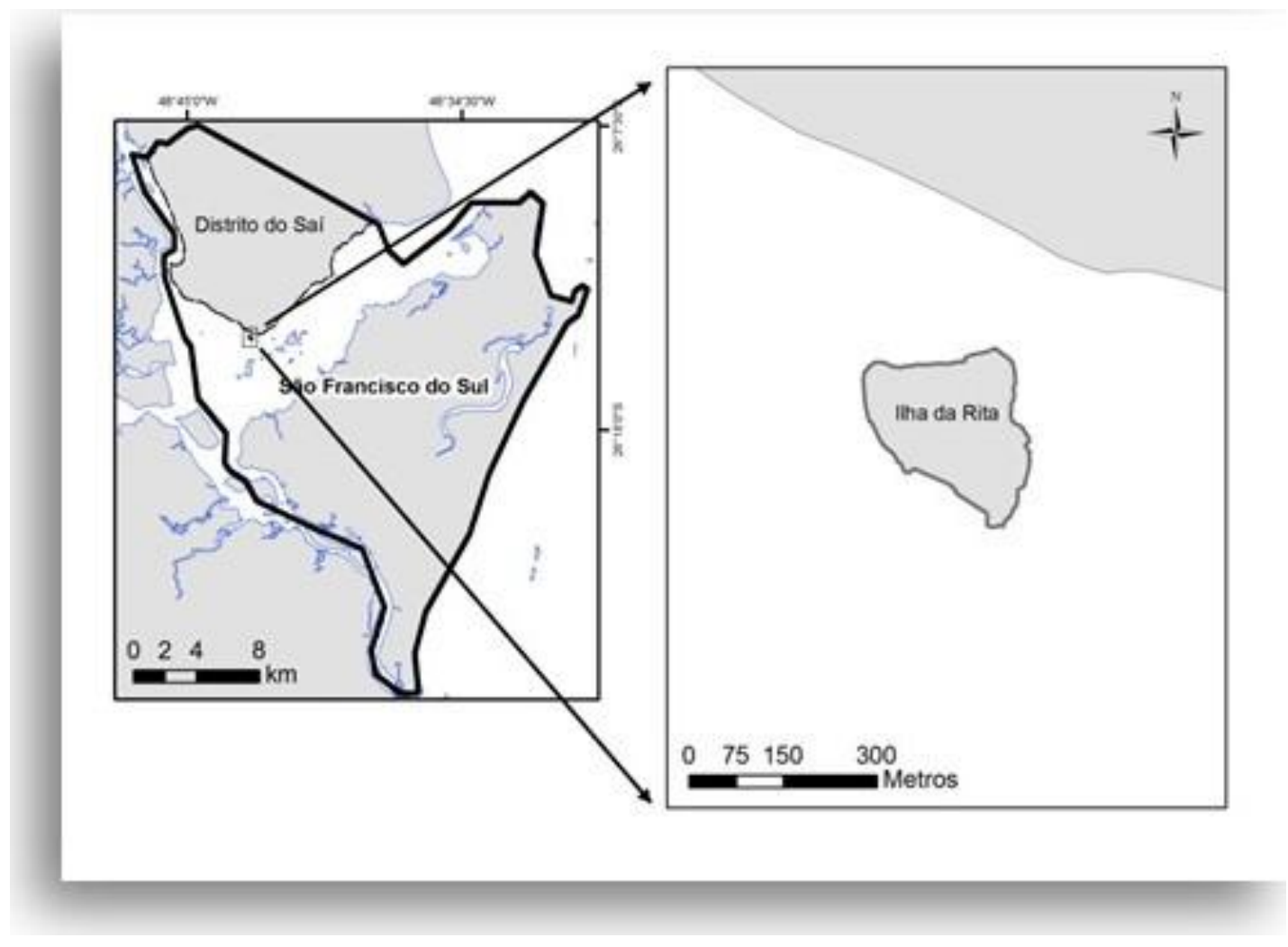

Figura 5: Localização da Ilha da Rita.

Fonte: André Lima, Grupo de Estudos Interdisciplinares de Patrimônio Cultural, 2013.

A Ilha da Rita atingiu seu auge de utilização durante a Segunda Guerra Mundial e funcionou entre as décadas de 1940 e 1960. Fuzileiros de diversas partes do Brasil serviram ali neste período, contribuindo com intercâmbio cultural na região entre os habitantes da Ilha, do Distrito do Saí e de São Francisco do Sul (THIAGO; COELHO, 2001). Como a Ilha foi perdendo sua função como base naval com o fim da Segunda Guerra Mundial, em 1968 a Marinha resolveu desativá-la e devolvê-la à União. A Ilha da Rita passou então à responsabilidade do Porto de São Francisco do Sul, que continuou utilizando-a como posto de abastecimento de navios. A modernização do Porto e dos navios fez com que sua função principal, o abastecimento, fosse perdida. Com a intenção do Porto em devolver a Ilha da Rita à União e a manifestação de interesse por parte da Universidade da Região de Joinville - Univille, a mesma recebeu a cessão da Ilha da Rita por 99 anos (THIAGO; COELHO, 2001) e vem realizando diversos estudos no local que tem envolvido os moradores do Distrito do Saí. 


\section{Considerações finais}

Acredita-se que as questões que envolvem a gestão do patrimônio cultural devem considerar as demandas da população acreditando que "a implementação de políticas patrimoniais deve partir dos anseios da comunidade e ser norteada pela delimitação democrática dos bens reconhecidos como merecedores de preservação" (FUNARI; PELEGRINI, 2006, p. 59). Diante disso, esse estudo das representações sociais, auxiliado pelo geoprocessamento, possibilita que sejam desenvolvidas as potencialidades do patrimônio cultural em relação ao local em que está inserido, à população e ao conhecimento das relações que se estabelecem entre ela e seu patrimônio.

Localizado fora do Centro Histórico tombado, o patrimônio cultural do Distrito do Saí é pouco conhecido, e através das metodologias empregadas na análise das representações sociais foi possível identificar quais são as unidades reconhecidas pela população e registrá-las. A partir deste reconhecimento social do patrimônio cultural do Distrito do Saí e identificação geográfica, será possível favorecer a gestão do mesmo através de medidas que visem sua preservação, seja ela através dos processos de tombamento ou registro, bem como o desenvolvimento de atividades relacionadas à educação patrimonial e ao turismo, fomentando a cultura local e também a economia.

Os mapas elaborados, bem como a base cartográfica produzida poderão ser utilizados em consultas de viabilidade para implantação de novos empreendimentos, bem como para a criação de unidades de preservação municipal. Dada a versatilidade das ferramentas de geoprocessamento, a mesma metodologia adotada para o mapeamento do Patrimônio Cultural do Distrito do Saí, poderá ser aplicada em outros setores da prefeitura, bem como pode ser utilizada por outros municípios.

Por fim, cabe ainda ressaltar a complexidade e a relevância do estudo interdisciplinar do patrimônio cultural a partir da teoria das representações sociais, buscando compreender os diversos aspectos relacionados à constituição e a seu reconhecimento pela sociedade.

\section{Referências bibliográficas}

ALVES, M. C.; MARTINS, F. C. Obras de Pavimentação Asfáltica de Estradas Municipais em Joinville e São Francisco do Sul. Joinville: OAP, 2006. BORBA, F. M. Arqueologia da escravidão numa vila litorânea: vestígios negros em São Francisco do Sul. Editora da Univille: Joinville, 2014.

BRASIL. Lei $\mathbf{n}^{\mathbf{0}} \mathbf{1 0 . 2 5 7}$ de 10 de Julho de 2001.Regulamenta os arts. 182 e 183 da Constituição Federal, estabelece diretrizes gerais da política urbana e dá outras providências, Brasília. Disponível em:http://www.planalto.gov.br/ccivil_03/leis/LEIS_2001/L10257.htm Acesso em 14/12/2012. Legislação Federal.

BRASIL. Lei $\mathbf{n}^{0} 6.766$ de 19 de dezembro de 1979. Dispõe sobre o parcelamento do Solo e dá outras providências, Brasília. Disponível em: 
http://www.planalto.gov.br/ccivil_03/leis/LEIS_2001/L10257.htmAcesso em 14/12/2012. Legislação Federal.

ESRI. ENVIRONMENTAL SYSTEMS RESEARCH INSTITUTE, ArcGIS for desktop, version 10. Software. 2010.

FERREIRA, F. C. et al. O Papel do Geoprocessamento na preservação do Patrimônio Cultural nacional nos municípios de Porto Seguro e Santa Cruz Cabrália, Bahia: procedimentos e desafios In: XV Simpósio brasileiro de Sensoriamento Remoto SBSR, Curitiba: INPE, 2011.

FUNARI, P. P. A.; PELLEGRINI, S. Patrimônio Histórico e Cultural. Rio de Janeiro: Jorge Zahar Editor, 2006.

MOSCOVICI, S. Representações Sociais: Investigações em Psicologia Social. 6. ed. Petrópolis: Vozes, 2009.

MOURA, A. C. M. Geoprocessamento aplicado ao planejamento urbano e à gestão do patrimônio histórico de Ouro Preto-MG. In: Anais do XXI Congresso Brasileiro de Cartografia. Rio de Janeiro: Sociedade Brasileira de Cartografia, 2003. v. 1. p. 1-9.

PELLEGRINI, S. C. A. Patrimônio cultural: consciência e preservação. São Paulo: Brasiliense, 2009.

OLIVEIRA, R. N. de. O Patrimônio Cultural da Base Naval da Ilha da Rita: Defesa, Segurança Nacional e o Perigo Alemão na Primeira Metade do Século XX. 2013. Dissertação (Mestrado em Patrimônio Cultural e Sociedade - Universidade da Região de Joinville), Joinville, SC.

RODRÍGUEZ, E. R. (Org). Representaciones sociales: atisbos, cabilacionesdeldevenir de cuatro décadas. México: Benemérita Universidad Autónoma de Puebla, 2004.

SALVADORI, M. A. B. História, ensino e patrimônio. Araraquara: Junqueira \& Marin, 2008.

SILVA, R. C. Representações sociais sobre o centro histórico tombado de São Francisco do Sul. 2010. 125 p. Dissertação (Mestrado em Patrimônio Cultural e Sociedade - Universidade da Região de Joinville), Joinville, SC

THIAGO, R. S.; COELHO, I. A Univille na história da paisagem da Ilha da Rita. Revista Univille, Joinville (SC), v.6, n.2, p. 49-62, 2001. 